\title{
Aqueous garlic extract protects against sepsis-induced toxicity in pulmonary and ileal tissues
}

\author{
Sevil Ozkan ${ }^{1 *}$, Tugba Tunali Akbay ${ }^{2}$, Selin Sakarcan ${ }^{3}$, Emre Gunay ${ }^{4}$, Goksel Sener ${ }^{5}$
}

\begin{abstract}
Objective: Based on the potent antioxidant effects of aqueous garlic extract (AGE), the present study was designed to characterize the potential of AGE to modify blood coagulation parameters as well as and pulmonary and ileal injury in septic rats. Sepsis was induced using the caecal ligation and perforation (CLP) method.
\end{abstract}

Material and Method: Twenty-four hours after sepsisinduction, rats were decapitated and trunk blood was collected for the measurement of platelet counts, fibrinogen, prothrombin time, activated partial thromboplastin time (APTT) and d-dimer levels. Then, pulmonary and ileal tissue samples were immediately obtained and stored at $-70{ }^{\circ} \mathrm{C}$ for malondialdehyde (MDA), glutathione (GSH), myeloperoxidase (MPO) and superoxide dismutase (SOD) activity assays.

Results: Sepsis was associated with a decrease in platelet count and fibrinogen and an increase in APTT and International normalized ratio. It also caused a significant decrease in GSH levels and SOD activity in both pulmonary and ileal tissue samples. On the other hand, AGE treatment in rats with CLP caused significantly augmented the level of these antioxidants. As a result of CLP induction increased MPO activity and MDA levels and decreased thromboplastic activity were reversed with AGE treatment.

Conclusion: AGE treatment, through its antioxidant effects, protects against oxidative pulmonary and ileal injury and normalizes the impaired coagulation in sepsis.

Keywords: Oxidative stress, thromboplastic activity, septic, rat, pulmonary injury, ileal injury

\section{Introduction}

Septic shock is an infectious complication in which toxins initiate an inflammatory response involving all systems. Therefore, it is defined as an excessive and irregular systemic inflammatory response to an infectious state, involving various organ systems, that leads to hemodynamic changes, and ultimately results in shock, organ failure or even death. Excessive production of reactive oxygen species (ROS) by activated immune cells causes oxidative damage, which is thought to play a significant role in the pathogenesis of sepsis induced organ damage $(1,2)$. These radicals lead to lipid peroxidation, impair cell membranes, and give rise to oxidative damage in deoxyribonucleic acid and proteins (3). Several experimental and clinical studies have shown beneficial effects of antioxidants in preventing organ failure and decreasing mortality in sepsis $(4,5)$.
Garlic Allium sativum 'A. sativum' has been widely used as a foodstuff and also a traditional medicine for many centuries throughout the world (6). The antibacterial effects of garlic against a wide range of bacteria (7) and the intrinsic antioxidant activity of garlic, garlic extracts and some garlic constituents (8-10) have been widely documented in vivo $(11,12)$ and in vitro $(8,13)$. Furthermore, garlic acts as an enhancer of cellular antioxidant enzymes; superoxide dismutase (SOD), catalase, and glutathione (GSH) peroxidase, in addition to increasing cellular GSH levels (14-16). These properties of garlic increase the antioxidant capacity of the body and provide effective scavenging of free radicals, thereby improving immunity $(17,18)$.

Based on the potent antibacterial and antioxidant effects of garlic, we investigated the putative protective role of aqueous

\footnotetext{
Received: 25-02-2016, Accepted: 11-03-2016

${ }^{1}$ Haydarpasa Numune Education and Research Hospital, Clinic of Internal Medicine, Istanbul-Turkey

${ }^{2}$ Marmara University Faculty of Medicine, Department of Medical Biochemistry, Istanbul-Turkey

${ }^{3}$ Temple University Faculty of Medicine, Department of Microbiology, Pennsylvania-USA

${ }^{4}$ Haydarpasa Numune Education and Research Hospital, Clinic of General Surgery, Istanbul-Turkey

${ }^{5}$ Marmara University Faculty of Pharmacy, Department of Pharmacology, Istanbul-Turkey

*Corresponding Author: Sevil Ozkan E-mail: sevilozkan@hotmail.com
} 
garlic extract (AGE) against sepsis-induced oxidative damage in pulmonary and ileal tissues as well as its effects on certain coagulation parameters.

\section{Material and Methods}

\section{Animals}

Wistar albino rats of either sex, weighing 200 to $250 \mathrm{~g}$, were kept in a room at a constant temperature $\left(22 \pm 2{ }^{\circ} \mathrm{C}\right)$ with 12 -h light and dark cycles and were fed a standard rat chow. Rats were fasted for $12 \mathrm{~h}$ before experiments, but were allowed free access to water. Experimental protocol was approved by the Marmara University Animal Care and Ethics Committee.

Preparation of garlic extract

Garlic, from which the study preparations were derived, was harvested in August from Kastamonu region of Turkey and was kept in dry storage conditions protected from light. Peeled garlic (30 g) was crushed with distilled water in a mortar. The crushed material was carefully decanted by pressing, and 60 $\mathrm{mL}$ of aqueous extract was extracted. One milliliter of aqueous extract contained material from $500 \mathrm{mg}$ of garlic $(19,20)$. The aqueous extract was stored at $4{ }^{\circ} \mathrm{C}$.

\section{Experimental protocol and induction of sepsis}

Rats were divided into four groups, 2 control and 2 sepsis groups, with 8 animals in each. Rats were supplemented with either saline or AGE ( $250 \mathrm{mg} / \mathrm{kg} /$ day orally) for 15 days prior to sham operation or caecal ligation and perforation (CLP), and also immediately postoperatively.

In the sham operated control groups, after laparotomy, the cecum was manipulated but left intact (without ligation or perforation). In the sepsis groups rats underwent CLP technique according to the method described by Fujimura et al. (21). Briefly, under ether anesthesia, a midline laparotomy was made using minimal dissection and the cecum was ligated just below the ileocaecal valve with 3-0 silk ligatures so that intestinal continuity was maintained. On the antimesentric surface of the cecum, using an 18-gauge needle, the cecum was perforated at two locations $1 \mathrm{~cm}$ apart and the cecum was gently compressed until the feces were extruded. The bowel was then returned to the abdomen and the incision was closed. At the end of the operation, all rats were resuscitated with saline $(3 \mathrm{~mL} / 100 \mathrm{~g}$ body weight) administered subcutaneously.

Twenty-four hours after the sepsis-induction, rats were decapitated and trunk blood was collected for the measurement of platelet counts, fibrinogen, International normalized ratio (INR) and activated partial thromboplastin time (APTT) levels. Furthermore lung and ileum tissue samples were immediately taken and stored at $-70{ }^{\circ} \mathrm{C}$ to analyze SOD, myeloperoxidase (MPO), and thromboplastic activities, as well as malondialdehyde (MDA) and GSH levels.

\section{Determination of coagulation parameters in blood}

Trunk blood was collected into plastic syringes containing onetenth in a volume of $3.8 \%(\mathrm{w} / \mathrm{v})$ trisodium citrate or into plastic syringes containing sodium ethylenediaminetetraacetic acid (EDTA). Blood samples taken into $3 \cdot 8 \%(\mathrm{w} / \mathrm{v})$ trisodium citrate were centrifuged at $2000 \mathrm{~g}$ for $10 \mathrm{~min}$ for the measurement of prothrombin time (prothrombin time, INR) (Cat. no. 52601003, Agappe, Switzerland), APTT (Cat. no. 52602001, Agappe, Switzerland), fibrinogen (Cat. no. 840155, Pacific Hemostasis, UK), and d-dimer (Cat. no. D2050-000, Teco, Germany). In d-dimer test, agglutination occurs within 180-200 seconds for samples containing more than $250 \mathrm{ng} / \mathrm{mL}$. If agglutination is observed within 180-200 seconds a pathological condition probably exists. Platelet count was determined in the whole blood samples drawn into sodium EDTA by using an automated analyzer (KT 6200 VET, Genius, China).

\section{Measurement of tissue superoxide dismutase activity}

SOD activity in the lung and ileum tissue samples was measured in accordance with a previously described method (22). Briefly, measurements were performed in cuvettes containing $2.8 \mathrm{~mL}$ $50 \mathrm{mM}$ potassium phosphate $(\mathrm{pH}=7.8)$ with $0.1 \mathrm{mM}$ EDTA, $0.1 \mathrm{mM} 0.39 \mathrm{mM}$ riboflavin in $10 \mathrm{mM}$ potassium phosphate $(\mathrm{pH}=7.5), 0.1 \mathrm{~mL}$ of $6 \mathrm{mM} \mathrm{O}$-dianisidin. $2 \mathrm{HCl}$ in deionized water, and tissue extract $(50,100 \mathrm{~mL})$. Cuvettes with all their components were illuminated with 20 -W Sylvania Grow Lux fluorescent tubes that were placed $5 \mathrm{~cm}$ above and to one side of cuvettes maintaining a temperature of $37^{\circ} \mathrm{C}$. Absorbance were measured at $460 \mathrm{~nm}$ with a Shimadzu UV-02 model spectrophotometer. A standard curve was prepared routinely with bovine SOD (Sigma Chemical Co, ST-2515-3000 U) as reference. Absorbance readings were taken at 0 and $8 \mathrm{~min}$ of illumination and the net absorbance were calculated.

\section{Measurement of tissue myeloperoxidase activity}

MPO activity was measured in tissues in a procedure similar to that documented by Hillegass et al. (23). Tissue samples were homogenized in $50 \mathrm{mM}$ potassium phosphate buffer ( $\mathrm{PB}, \mathrm{pH}=6.0)$, and centrifuged at 41,400 $\mathrm{g}$ (10 $\mathrm{min})$; pellets were suspended in $50 \mathrm{mM} \mathrm{PB}$ containing $0.5 \%$ hexadecyltrimethylammonium bromide. After three freeze and thaw cycles, with sonication between cycles, the samples were centrifuged at $41,400 \mathrm{~g}$ for $10 \mathrm{~min}$. Aliquots $(0.3 \mathrm{~mL})$ were added to $2.3 \mathrm{~mL}$ of reaction mixture containing $50 \mathrm{mM} \mathrm{PB}$, $\mathrm{O}$-dianisidine, and $20 \mathrm{mM} \mathrm{H}_{2} \mathrm{O}_{2}$ solution. One unit of enzyme activity was defined as the amount of MPO present that caused a change in absorbance measured at $460 \mathrm{~nm}$ for $3 \mathrm{~min}$. MPO activity was expressed as $\mathrm{U} / \mathrm{g}$ tissue. 


\section{Measurement of tissue thromboplastic activity}

Thromboplastic activity of lung and ileum tissues was evaluated according to Quick's onestage method using normal plasma (24). This was performed by mixing $0.1 \mathrm{~mL}$ tissue homogenate with $0.1 \mathrm{~mL} 0.02 \mathrm{M} \mathrm{CaCl}_{2}$; the clotting reaction was started upon the addition of $0.1 \mathrm{~mL}$ plasma. All reagents were brought to the reaction temperature $\left(37^{\circ} \mathrm{C}\right)$ before mixing. Thromboplastic activity was expressed as seconds. The lengthening of the clotting time is an indication of decreased tissue factor (TF) activity.

Measurement of tissue malondialdehyde and glutathione levels

Lung and ileum tissue samples were homogenized with ice-cold $150 \mathrm{mM}$ chloride for the determination of MDA and GSH levels. MDA levels were assayed for products of lipid peroxidation by monitoring thiobarbituric acid reactive substance formation as described previously (25). Lipid peroxidation was expressed in terms of MDA equivalents using an extinction coefficient of $1.56 \times 10^{5} \mathrm{M}^{-1} \mathrm{~cm}^{-1}$ and results are expressed as nmol MDA/g tissue. GSH measurements were performed using a modification of the Ellman procedure (26). Briefly, after centrifugation at $3000 \mathrm{rev} / \mathrm{min}$ for $10 \mathrm{~min}, 0.5 \mathrm{~mL}$ of supernatant was added to $2 \mathrm{~mL}$ of $0.3 \mathrm{~mol} / 1 \mathrm{Na}_{2} \mathrm{HPO}_{4} .2 \mathrm{H}_{2} \mathrm{O}$ solution. A $0.2 \mathrm{~mL}$ solution of dithiobisnitrobenzoate $(0.4 \mathrm{mg} / \mathrm{mL} 1 \%$ sodium citrate) was added and the absorbance at $412 \mathrm{~nm}$ was measured immediately after mixing. GSH levels were calculated using an extinction coefficient of $1.36 \times 104 \mathrm{M}^{-1} \mathrm{~cm}^{-1}$. Results are expressed in $\mu \mathrm{mol} \mathrm{GSH} / \mathrm{g}$ tissue.

\section{Statistical analysis}

Statistical analysis was carried out using GraphPad Prism 5.0 (GraphPad Software, San Diego, CA, USA) and all data were expressed as means \pm standard error of mean. Groups of data were compared with an analysis of variance (ANOVA) followed by Tukey's multiple comparison tests. A p value of less than 0.05 was considered significant.

\section{Results}

As shown in Table 1 sepsis was associated with reduced platelet and fibrinogen, and increased APTT and INR levels. D-dimer levels also increased after sepsis induction (Table 2). On the other hand AGE treatment did not have a significant effect on these parameters except for d-dimer, which was significantly reduced by AGE treatment (Table 2).

Sepsis induced significant decrease in GSH and SOD in both lung ( $p<0.001$, Figure 1$)$ and ileum $(p<0.01$, Figure 2$)$ tissue samples, while AGE treatment in rats with CLP gave rise to significant increases in both of these antioxidants $(p<0.5)$.
As a result of CLP induction, MPO activity and MDA levels were found to increase in both lung and ileum tissues $(\mathrm{p}<0.001$, Figure 3 and Figure 4, respectively). On the other hand, AGE treatment in the CLP group caused a decline in these values $(p<0.005-0.001)$ restoring baseline levels.

Since the clotting time is inversely proportional to the TF activity, prolonged clotting time is indicative of decreased $\mathrm{TF}$ activity. Accordingly, CLP caused decrease in TF activity of lung and ileum tissues $(p<0.001$, Figure $3 c, 4 c)$. On the other hand $\mathrm{AGE}$ treatment in CLP rats caused an increase in TF activity in both lung $(\mathrm{p}<0.05)$ and ileum $(\mathrm{p}<0.001)$ tissues.

Saline-treated

AGE-treated

a)

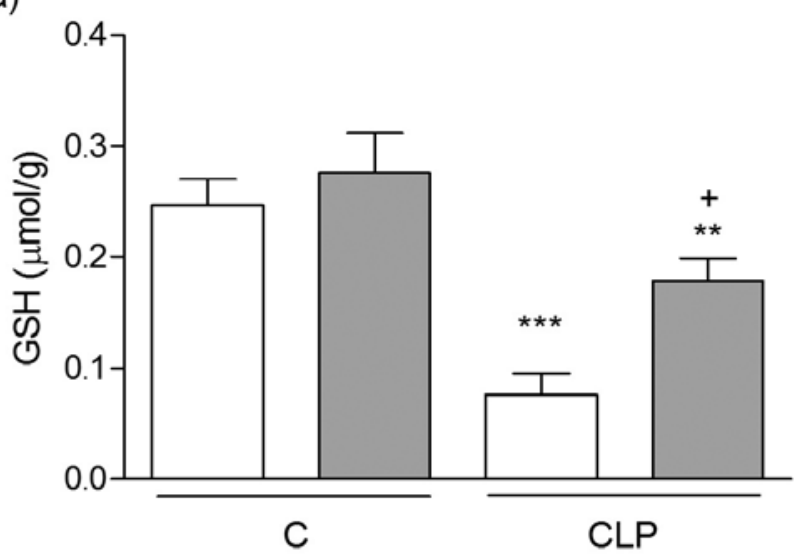

b)

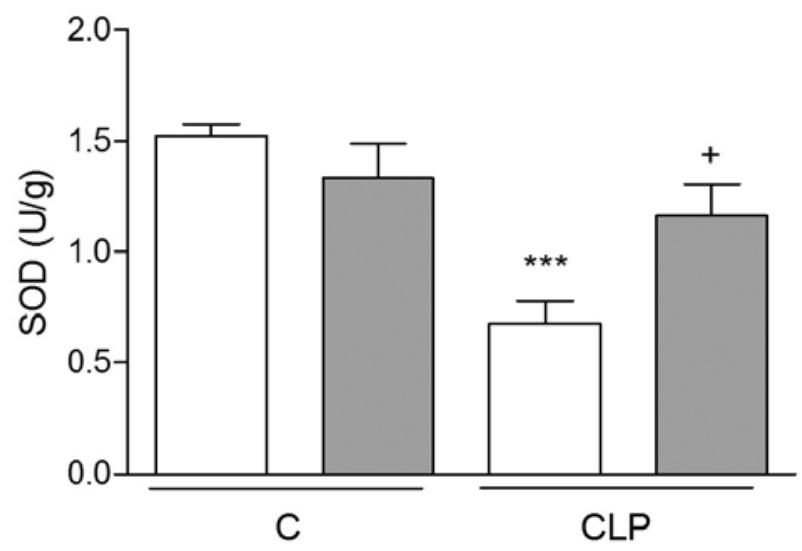

Figure 1. Glutathione levels and b) Superoxide dismutase activities in the lung tissue samples of saline-and aqueous garlic extracttreated control and sepsis groups, $* * p<0.01, * * * p<0.001$ versus saline-treated control group, ${ }^{+} \mathrm{p}<0.05$ versus saline treated-sepsis group, for each group n=8, GSH: Glutathione, SOD: Superoxide dismutase, CLP: Caecal ligation and perforation, AGE: Aqueous garlic extract 


\section{Discussion}

Being one of the most popular herbal remedies, garlic has been widely used for the treatment of diseases since ancient times, despite the scarcity of data in the current literature on the effects of AGE on pulmonary and ileal tissues in sepsis. In the present study, pulmonary and ileal pathologic changes induced by oxidative damage due to experimentally-induced sepsis and the potential protective effects of AGE against this damage were investigated. Our results showed an alleviation of sepsis-induced oxidative damage in the lung and intestinal tissues by AGE, as suggested by significantly reduced MDA and MPO levels and increased GSH and SOD. Furthermore, thromboplastic activity, which decreased due to sepsis, was augmented by AGE

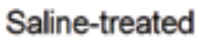

AGE-treated

a)

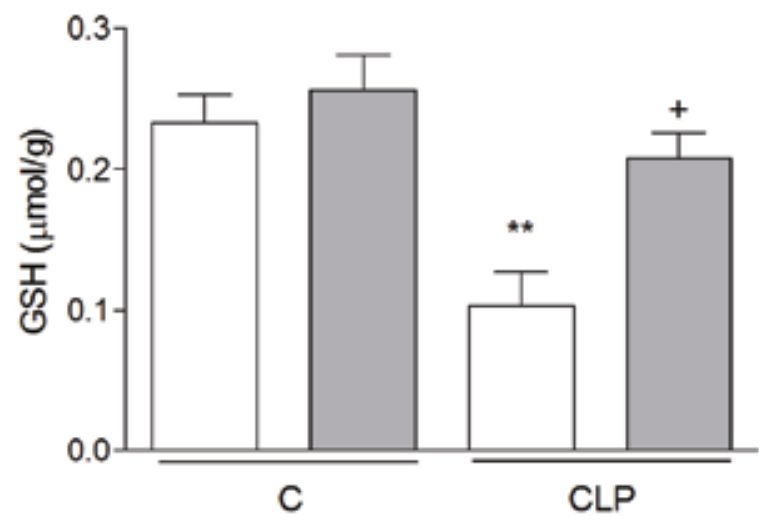

b)

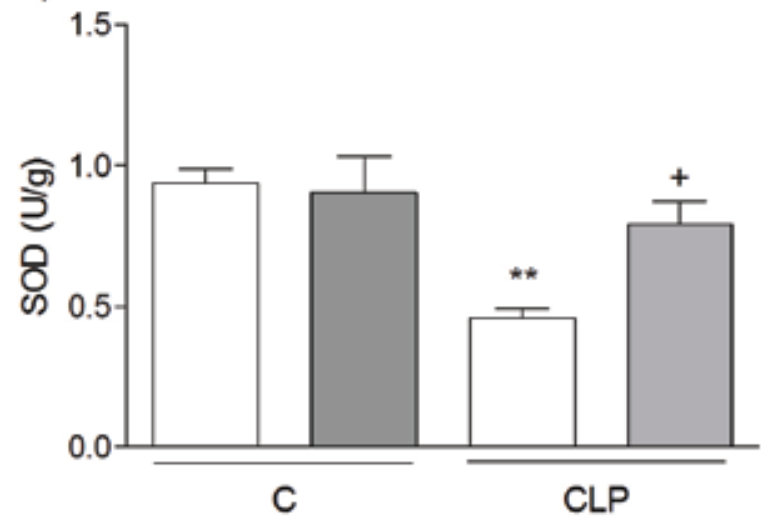

Figure 2. Glutathione levels and b) Superoxide dismutase activities in the ileal tissue samples of saline-and aqueous garlic extracttreated control and sepsis groups, ${ }^{*} * \mathrm{p}<0.01$ versus saline-treated control group, ${ }^{+} \mathrm{p}<0.05$ versus saline treated-sepsis group, for each group n=8, GSH: Glutathione, SOD: Superoxide dismutase, CLP: Caecal ligation and perforation, AGE: Aqueous garlic extract
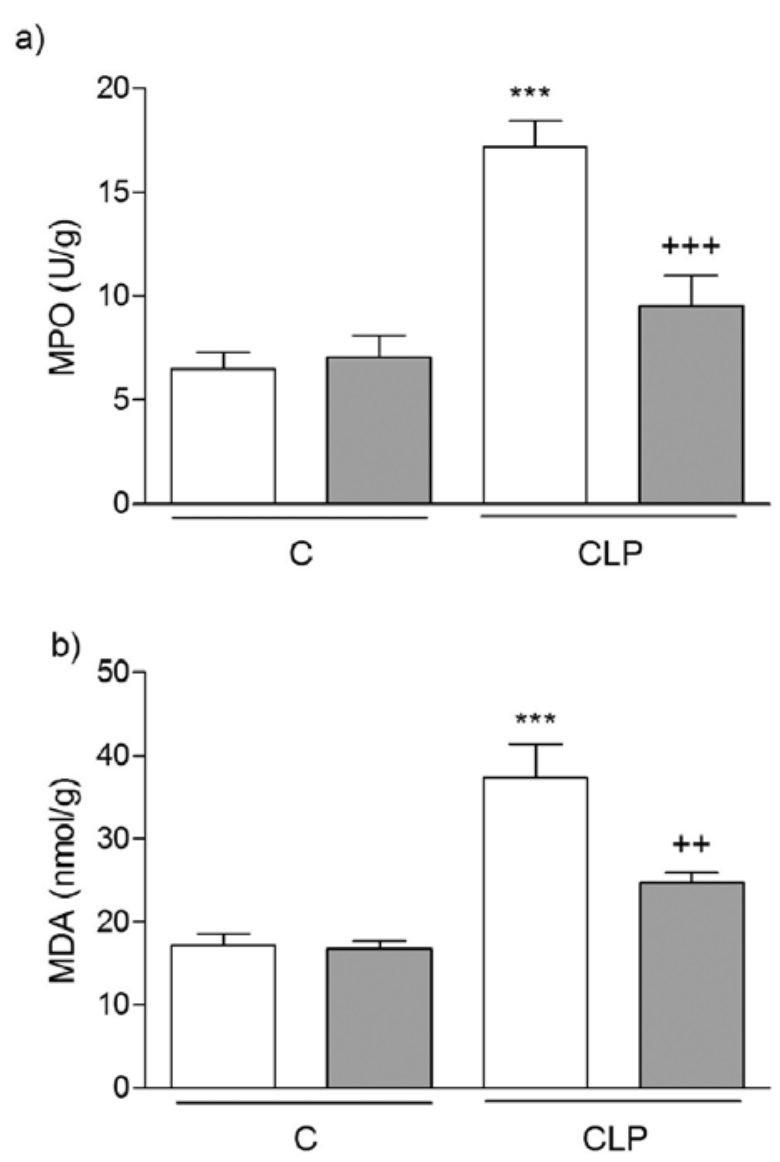

c)

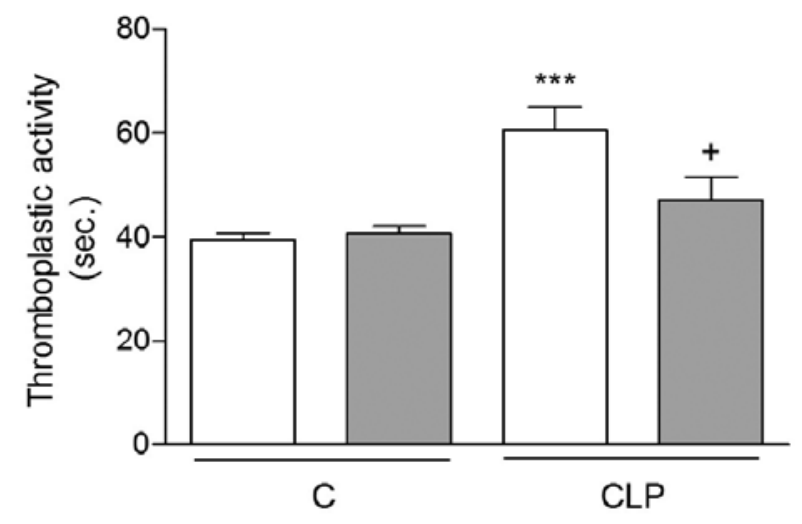

Figure 3. Myeloperoxidase activities, b) Malondialdehyde levels and c) Thromboplastic activities in the lung tissues of salineand aqueous garlic extract-treated control and sepsis groups, ${ }^{* * *} \mathrm{p}<0.001$ versus saline-treated control group, ${ }^{+} \mathrm{p}<0.05$, ${ }^{++} \mathrm{p}<0.01,{ }^{+++} \mathrm{p}<0.001$ versus saline treated-sepsis group, for each group $\mathrm{n}=8$, MPO: Myeloperoxidase, MDA: Malondialdehyde, CLP: Caecal ligation and perforation, AGE: Aqueous garlic extract 


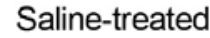

AGE- treated

a)

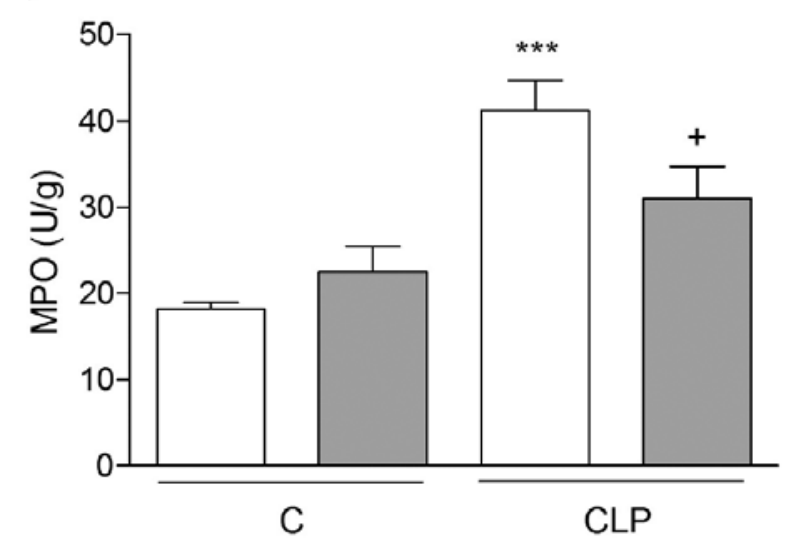

b)

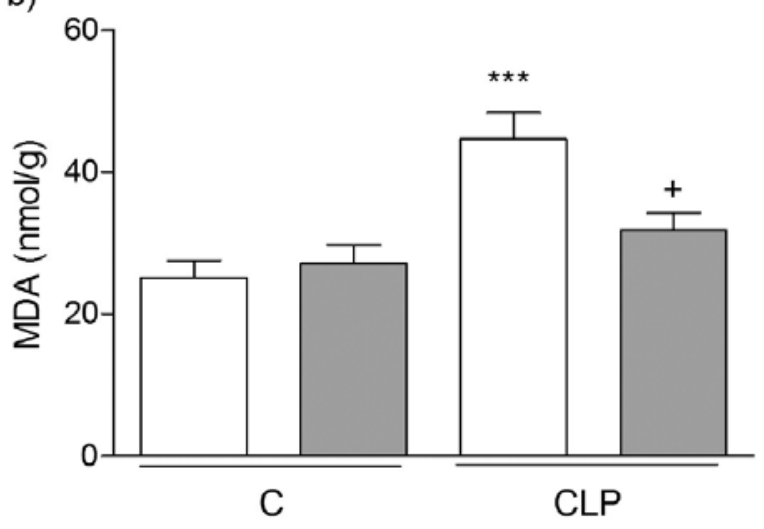

C)

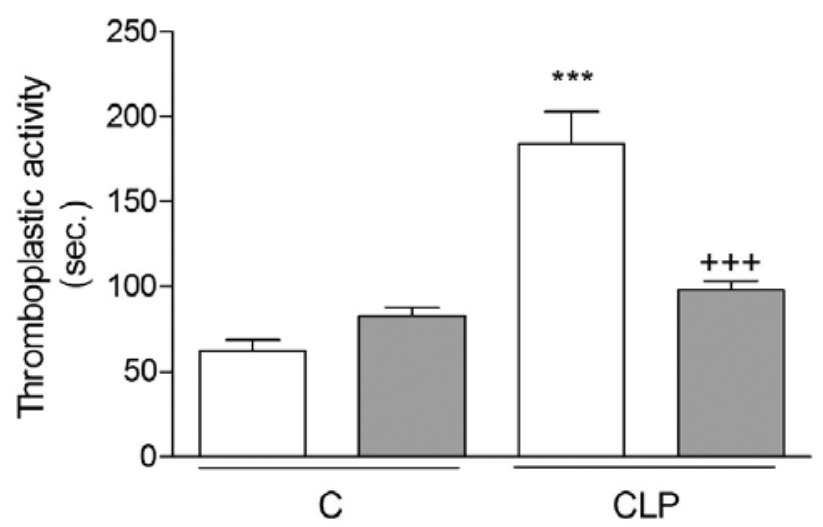

Figure 4. Myeloperoxidase activities, b) Malondialdehyde levels and c) Thromboplastic activities in the ileal tissues of salineand aqueous garlic extract-treated control and sepsis groups, $* * * p<0.001$ versus saline-treated control group, ${ }^{+} \mathrm{p}<0.05$, ${ }^{+++} \mathrm{p}<0.001$ versus saline treated-sepsis group, for each group $\mathrm{n}=8$, MPO: Myeloperoxidase, MDA: Malondialdehyde, CLP: Caecal ligation and perforation, AGE: Aqueous garlic extract treatment and the sepsis-induced reduction in platelet count was partially reversed. On the other hand, INR and APTT, which were elevated in septic rats, were significantly decreased by AGE treatment. AGE treatment did not affect fibrinogen and d-dimer levels, which were decreased and elevated, respectively, during sepsis. Garlic containing preparations have recently been shown to exert beneficial effects against tumor promotion (27), in cardiovascular disorders, in hepatic damage (28) and in the process of aging (29) and these effects were mostly attributed to its anti-oxidant properties. Preventive or therapeutic strategies that incorporate the use of AGE might arguably be developed in this condition, considering the fact that sepsis is associated with oxidative damage in various organs (30) and that garlic is known to have antioxidant properties.

Sepsis is a generalized inflammatory response, involving various organ systems and causing disturbance of homeostasis through a currently uncontrollable cascade of excessive inflammation and coagulation with impaired fibrinolysis that contributes to an inflammatory response, microvascular hypoperfusion, organ dysfunction, and increased mortality. The magnitude of disruption in homeostasis is influenced by the virulence of the causative pathogens and the host's response to the infection (31-33). In this regard, the results of the present study are consistent with the above-mentioned hemostatic disturbance in sepsis. On the other hand, although garlic has been shown to have antithrombotic and antiplatelet properties $(34,35)$, in the present study AGE decreased the platelet count only in the control group without an antithrombotic effect. However reversal of the sepsis-induced changes in platelet count, INR, APTT and d-dimer level by AGE treatment suggests that these effects of AGE in sepsis may not be directly linked with its antithrombotic and antiplatelet effects, and rather may stem from its antioxidant and antibacterial effects.

The CLP are widely used for the induction of sepsis in models of sepsis based on its clinical resemblance to sepsis in humans. Recent studies have shown that sepsis is associated with the enhanced generation of reactive oxygen metabolites (ROMs), leading to multiple organ dysfunction $(36,37)$, most marked in lungs, liver, kidneys, heart, and intestines. These pathological changes are known to result from bacterial invasion, direct effects of bacterial toxins and enzymes, effects of mediators, impaired perfusion, and disseminated intravascular coagulation (38). Pulmonary involvement occurs early in sepsis and pulmonary complications are major factor contributing to poor prognosis. After pulmonary involvement, other common pathological conditions include the acute ischemic colitis in the intestines and zonal necrosis of the liver $(39,40)$.

Lipids are a major target of free oxygen radicals, which initiate lipid peroxidation by receiving a hydrogen atom from 
polyunsaturated fatty acids, giving rise to the formation of hydrogen peroxide. The result of this process is the disrupted cell membrane fluidity followed by cell death (41). In the present study, the levels of MDA, an end-product of lipid peroxidation, were significantly increased in pulmonary and ileal tissues, in line with the previous studies, in which elevated levels of lipid peroxidation products were increased from $40 \%$ to $80 \%$ above basal values as a result of oxidative stress $(30,42,43)$. On the other hand, AGE treatment inhibited MDA elevations and restored the control levels suggesting that AGE might be protective against organ damage by maintaining cellular integrity.

There are enzymatic and non-enzymatic antioxidant mechanisms involved the removal of free radicals and for damage repair. Among enzymatic antioxidants, SOD is particularly important for intracellular killing of phagocytized bacteria and for granulocyte function (44). It catalyzes the conversion of superoxide to hydrogen peroxide and is primarily protective against oxyradicals. GSH, on the other hand, a non-enzymatic antioxidant, is an important constituent of intracellular protective mechanisms against various noxious stimuli including oxidative stress (45). In a previous study by our team, CLP was shown to cause significant decrease in GSH levels, which was reversed by the powerful antioxidant melatonin (46). Furthermore we also demonstrated that following a variety of various oxidative insults resulting in depletion of GSH, repletion could be accomplished by AGE $(19,47)$. Similarly, Kilikdar et al. (28) demonstrated that AGE treatment provided an elevation in SOD activity in lead -induced hepatic injury in rats. In our study, pulmonary and ileal tissue GSH levels and SOD activities were lower in the sepsis group as compared to the control group, while AGE was effective in replenishing these antioxidants.
Studies have demonstrated that neutrophils are one of the major sources of ROMs (48). The heme enzyme MPO, found in neutrophils, uses a superoxide anion to produce hypochlorous acid, which is the major oxidant for its immune function. However, these MPO-derived oxidants also cause tissue and cellular damage (49). Thus, the tissue-associated MPO activity is considered to indicate the severity of inflammatory damage. Kettle and Winterbourn (50) suggested that inhibition of the enzyme activity could modulate the oxidant production and ultimately, tissue damage. In our study, increased MPO activity in both tissues suggests that neutrophil accumulation contributes to the sepsis-induced oxidative injury. Previously, in ischemia/ reperfusion-or naphthalene-induced oxidative stress models (51), increased MPO activities have been reported to decrease with AGE treatment. Similarly in our study, pulmonary and ileal tissue MPO activities were significantly higher in sepsis group as compared to the control group, while a significant decrease occurred in the sepsis group treated with AGE, suggesting an anti-inflammatory effect for AGE.

Thromboplastin (TF, factor III), the primary cellular initiator of blood coagulation, is a transmembrane receptor that is expressed in a tissue-specific manner (52). Moreover, various tissues and body fluids are known to harbor thromboplastic activity $(53,54)$. In the present study, although a significant decrease in the thromboplastic activity occurred in in the lung and pulmonary tissues in association with sepsis, AGE treatment resulted in a significant increase in thromboplastic activity in both tissues. Normalization of thromboplastic activity with AGE may also help eliminate the increased risk of bleeding due to the decreased thromboplastic activity in pulmonary and ileal tissues in sepsis.

Table 1: Platelet count, fibrinogen, International normalized ratio and activated partial thromboplastin time levels in plasma

\begin{tabular}{|l|l|l|l|l|}
\hline & \multicolumn{3}{|c|}{ C } & CLP \\
\hline & Saline-treated & AGE-treated & Saline-treated & AGE-treated \\
\hline Platelet count $\left(\mathrm{x} 10^{3} / \mathrm{mm}^{3}\right)$ & $493 \pm 17.1$ & $420 \pm 23.3^{*}$ & $205 \pm 10.4^{* * *}$ & $280 \pm 21.7^{* * *},{ }^{+}$ \\
\hline Fibrinogen $(\mathrm{mg} / \mathrm{dL})$ & $428 \pm 5.4$ & $389 \pm 31.9$ & $296 \pm 22.8^{* *}$ & $355 \pm 30.1$ \\
\hline INR & $1.06 \pm 0.04$ & $1.11 \pm 0.07$ & $1.84 \pm 0.13^{* * *}$ & $1.40 \pm 0.06^{+}$ \\
\hline APTT $(\mathrm{sec}$.) & $29.5 \pm 2.4$ & $35.7 \pm 3.0$ & $70.2 \pm 2.5^{* * *}$ & $54.4 \pm 1.3^{* * *},{ }^{+++}$ \\
\hline
\end{tabular}

$\mathrm{n}=8$ per group, ${ }^{*} \mathrm{p}<0.05,{ }^{* *} \mathrm{p}<0.01,{ }^{* * *} \mathrm{p}<0.001$ vs. control group, ${ }^{+} \mathrm{p}<0.05,{ }^{++} \mathrm{p}<0.001$ vs. saline-treated sepsis group, CLP: Caecal ligation and perforation, AGE: Aqueous garlic extract, INR: International normalized ratio, APTT: Activated partial thromboplastin time

Table 2: Changes in d-dimer for all groups

\begin{tabular}{|l|l|l|l|l|}
\hline \multirow{2}{*}{} & \multicolumn{2}{|c|}{ C } & \multicolumn{2}{c|}{ CLP } \\
\cline { 2 - 5 } & Saline-treated & AGE-treated & Saline-treated & AGE-treated \\
\hline D-dimer $(\mathrm{ng} / \mathrm{mL})$ & $<250$ & $<250$ & $>16000^{* * *}$ & $500-1000^{*}$ \\
\hline
\end{tabular}

$<250 \mathrm{ng} / \mathrm{mL}$ : There is no agglutination in undiluted and serial dilutions until 1:64 dilutions $500-1000 \mathrm{ng} / \mathrm{mL}$ : There is agglutination in 1:2 dilutions and there is no agglutination in serial dilutions until 1:64 dilutions $\mathrm{n}=8$ per group, ${ }^{*} \mathrm{p}<0.05,{ }^{* * *} \mathrm{p}<0.001$ vs. control group, CLP: Caecal ligation and perforation, AGE: Aqueous garlic extract 


\section{Conclusion}

In conclusion, the results of our study showed antioxidant and anti-inflammatory effects of AGE against tissue damage caused by free oxygen radicals and lipid peroxidation resulting from sepsis in an experimental rat model. However, further studies are warranted to better define the mechanisms of pulmonary and intestinal injury due to sepsis as well as the mechanisms of the benefit observed in AGE treatment.

Conflict of Interest: The authors declare that there is no conflict of interest arising out of this manuscript.

\section{References}

1. Goode HF, Webster NR. Free radicals and antioxidants in sepsis. Crit Care Med. 1993;21:1770-1776.

2. Crimi E, Sica V, Slutsky AS, Zhang H, Williams-Ignarro S, Ignarro LJ, et al. Role of oxidative stress in experimental sepsis and multisystem organ dysfunction. Free Radic Res. 20061;40:665-672.

3. Reiter RJ, Acuna-Castroviejo D, Tan DX, Burkhardt S. Free radicalmediated molecular damage. Mechanisms for the protective actions of melatonin in the central nervous system. Ann N Y Acad Sci. 2001;939:200-215.

4. Tavasoli S, Zarnani AH, Vafa M, Moradi-Lakeh M, Pazoki-Toroudi $\mathrm{H}$, Eghtesadi S. The effect of pomegranate extract on survival and peritoneal bacterial load in cecal ligation and perforation model of sepsis in rats. Int J Prev Med. 2014;5:104-109.

5. Yılmaz Savcun G, Ozkan E, Dulundu E, Topaloğlu U, Sehirli AO, Tok OE. Antioxidant and anti-inflammatory effects of curcumin against hepatorenal oxidative injury in an experimental sepsis model in rats. Ulus Travma Acil Cerrahi Derg. 2013;19:507-515.

6. Borek C. Antioxidant health effects of aged garlic extract. J Nutr. 2001;131:1010-1015

7. Goncagul G, Ayaz E. Antimicrobial effect of garlic (Allium sativum). Recent Pat Antiinfect Drug Discov. 2010;5:91-93.

8. Prasad K, Laxdal VA, Yu M, Raney BL. Evaluation of hydroxyl radicalscavenging property of garlic. Mol Cell Biochem. 1996;154:55-63.

9. Ide N, Matsuura H, Itakura Y. Scavenging effect of aged garlic extract and its constituents on active oxygen species. Phytother Res. 1996;10:340-341.

10. Rietz B, Isensee H, Strobach H, Makdessi S, Jacob R. Cardioprotective actions of wild garlic (Allium ursinum) in ischemia and reperfusion. Mol Cell Biochem. 1993;119:143-150.

11. Augusti KT, Sheela CG. Antiperoxide effect of S-allyl cysteine sulfoxide, an insulin secretagogue, in diabetic rats. Experimentia. 1996;52:115-120.
12. Iqbal M, Athar M. Attenuation of iron-nitrilotriacetate (Fe-NTA)mediated renal oxidative stress, toxicity and hyperproliferative response by the prophylatic treatment of rats with garlic oil. Food Chem Toxicol. 1998;36:485-495.

13. Rabinkov A, Miron T, Konstantinovski L, Wilchek M, Mirelman D, Weiner L. The mode of action of allicin: Trapping of radicals and interaction with thiol containing proteins. Biochem Biophys Acta. 1998;1379:233-244.

14. Geng Z, Lau BHS. Aged garlic extract modulates glutathione redox cycle and superoxide dismutase activity in vascular endothelial cells. Phytother Res. 1997;11:54-56.

15. Wei Z, Lau BHS. Garlic inhibits free radical generation and augments antioxidant enzyme activity in vascular endothelial cells. Nutr Res. 1998;18:61-70.

16. Sener G, Sakarcan A, Yegen BC. Role of garlic in the prevention of ischemia reperfusion injury. Mol Nutr Food Res. 2007;51:1345-1352.

17. Lamm DL, Riggs DR. Enhanced immunocompetence by garlic: Role in bladder cancer and other malignancies. J Nutr. 2001;131:1067-1070.

18. Sultan MT, Butt MS, Qayyum MM, Suleria HA. Immunity: Plants as effective mediators. Crit Rev Food Sci Nutr. 2014;54:1298-1308.

19. Sener G, Satiroglu H, Ozer Sehirli A, Kaçmaz A. Protective effect of aqueous garlic extract against oxidative organ damage in a rat model of thermal injury. Life Sci. 2003;73:81-91.

20. Batirel HF, Aktan S, Aykut C, Yeğen BC, Coşkun T. The effect of aqueous garlic extract on the levels of arachidonic acid metabolites (leukotriene $\mathrm{C} 4$ and prostoglandin E2) in rat forebrain after ischemiareperfusion injury. Prostaglandins Leukot Essent Fatty Acids. $1996 ; 54: 289-292$

21. Fujimura N, Sumita S, Aimono M, Masuda Y, Shichinohe Y, Narimatsu $\mathrm{E}$, et al. Effect of free radical scavengers on diaphragmatic contractility in septic peritonitis. Am J Respir Crit Care Med. 2000;162:2159-2165.

22. Mylroie AA, Collins H, Umbles C, Kyle J. Erythrocyte superoxide dismutase activity and other parameters of copper status in rats ingesting lead acetate. Toxicol Appl Pharmacol. 1986;82:512-520.

23. Hillegass LM, Griswold DE, Brickson B, Albrightson-Winslow C. Assessment of myeloperoxidase activity in whole rat kidney. J Pharmacol Methods. 1990;24:285-295.

24. Ingram GI, Hills M. Reference method for the one-stage prothrombin time test on human blood. International committee for standardization in hematology. Thromb Haemost. 1976;36:237-238.

25. Beuge JA, Aust SD. Microsomal lipid peroxidation. Methods Enzymol. 1978;52:302-310

26. Beutler E. Reduced glutathione (GSH). In: Beutler E, editor. Red cell metabolism, a manual of biochemical methods. New York: Grune and Straton; 1975:112-114. 
27. Agarwal MK, Iqbal M, Athar M. Garlic oil ameliorates ferric nitrilotriacetate (Fe-NTA)-induced damage and tumor promotion: Implications for cancer prevention. Food Chem Toxicol. 2007;45:16341640 .

28. Kilikdar D, Mukherjee D, Mitra E, Ghosh AK, Basu A, Chandra AM, et al. Protective effect of aqueous garlic extract against lead-induced hepatic injury in rats. Indian J Exp Biol. 2011;49:498-510.

29. Moriguchi T, Takashina K, Chu PJ, Saito H, Nishiyama N. Prolongation of life span and improved learning in the senescence accelerated mouse produced by aged garlic extract. Bioll Pharm Bull. 1994;17:1589-1594.

30. Iseri SO, Sener G, Saglam B, Gedik N, Ercan F, Yegen BC. Oxytocin protects against sepsis-induced multiple organ damage: Role of neutrophils. J SurgRes. 20051;126:73-81.

31. Vincent JL, Abraham E. The last 100 years of sepsis. Am J Res Crit Care Med. 20061;173:256-263.

32. Angus DC, Crowther MA. Unraveling severe sepsis: Why did OPTIMIST fail and what's next? JAMA. 2003;290:256-258.

33. Lopes-Bezerra LM, Filler SG. Endothelial cells, tissue factor and infectious diseases. Braz J Med Biol Res. 2003;36:987-991.

34. Vilahur G, Badimon L. Anti platelet properties of natural products. Vascul Pharmacol. 2013;59:67-75.

35. Mousa SA. Antithrombotic effects of naturally derived products on coagulation and platelet function. Methods Mol Biol. 2010;663:229-240.

36. Coskun AK, Yigiter M, Oral A, Odabasoglu F, Halici Z, Mentes $\mathrm{O}$, et al. The effects of montelukast on antioxidant enzymes and proinflammatory cytokines on the heart, liver, lungs, and kidneys in a rat model of cecal ligation and puncture-induced sepsis. Scientific World Journal. 2011;11:1341-1356.

37. Sener G, Sehirli O, Cetinel S, Ercan F, Yüksel M, Gedik N, et al. Amelioration of sepsis induced hepatic and ileal injury in rats by the leukotriene receptor blocker montelukast. Prostaglandins Leukot Essent Fatty Acids. 2005;73:453-462.

38. Wheeler AP, Bernard GR. Treating patients with severe sepsis. N Engl J Med. 1999;340:207-214.

39. Landmann R, Zimmerli W, Sansano S, Link S, Hahn A, Glauser MP, et al. Increased circulating soluble CD14 is associated with high mortality in gram-negative septic shock. J Infect Dis. 1995;171:639-644.

40. Wang H, Bloom O, Zhang M, Vishnubhakat JM, Ombrellino M, Che J, et al. HMG-1 as a late mediator of endotoxin lethality in mice. Science. 1999;285:248-251.
41. Stark G. Functional consequences of oxidative membrane damage. J Membr Biol. 2005;205:1-16.

42. Sener G, Sehirli O, Ipçi Y, Ercan F, Sirvanci S, Gedik N, et al. Aqueous garlic extract alleviates ischaemia reperfusion-induced oxidative hepatic injury in rats. J Pharm Pharmacol. 2005;57:145-150.

43. Kolgazi M, Sener G, Cetinel S, Gedik N, Alican I. Resveratrol reduces renal and lung injury caused by sepsis in rats. J Surg Res. 2006;134:315-321.

44. Johnston RB Jr, Keele BB Jr, Misra HP, Lehmeyer JE, Webb LS, Baehner RL, et al. The role of superoxide anion generation in phagocytic bactericidal activity. Studies with normal and chronic granulomatous disease leukocytes. J Clin Invest. 1975;55:1357-1372.

45. Ross D. Glutathione, free radicals and chemotherapeutic agents. Mechanisms of free radical induced toxicity and glutathione-dependent protection. Pharmacol Ther. 1988;37:231-249.

46. Sener G, Toklu H, Kapucu C, Ercan F, Erkanli G, Kaçmaz A, et al Melatonin protects against oxidative organ injury in a rat model of sepsis. Surg Today. 2005;35:52-59.

47. Deniz M, Şener G, Ercan F, Yeğen BÇ. Garlic extract ameliorates renal and cardiopulmonary injury in the rats with chronic renal failure. Ren Fail. 2011;33:718-725.

48. Weiss SJ. Tissue destruction by neutrophils. $\mathrm{N}$ Engl J Med. 1989;320:365-376.

49. Klebanoff SJ. Myeloperoxidase. Proc Assoc Am Physicians. 1999;111:383-389.

50. Kettle AJ, Winterbourn C. Myeloperoxidase: A key regulator of neutrophil oxidant production. Redox Rep. 1997;3:3-15.

51. Omurtag GZ, Güranlioğlu FD, Sehirli O, Arbak S, Uslu B, Gedik N, et al. Protective effect of aqueous garlic extract against naphthaleneinduced oxidative stress in mice. J Pharm Pharmacol. 2005;57:623-630.

52. Mackman N. Tissue-specific hemostasis in mice. Arterioscler Thromb Vasc Biol. 2005;25:2273-2281.

53. Yarat A, Tunali T, Pisiriciler R, Akyuz S, Ipbuker A, Emekli N. Salivary thromboplastic activity in diabetics and healthy controls. Clin Oral Investig. 2004;8:36-39.

54. Tunali Akbay T, Emiroglu A, Gul N, Yarat A. Effects of sodium bicarbonate induced blood $\mathrm{pH}$ change on oxidant status and thromboplastic activity of the kidney and lung. Asian $\mathrm{J}$ Chem. 2008;20:3182-3188

Copyright (C) 2016 The Author(s); This is an open-access article distributed under the terms of the Creative Commons Attribution License (http://creativecommons. org/licenses/by/4.0), which permits unrestricted use, distribution, and reproduction in any medium, provided the original work is properly cited. All Rights reserved by international journal of Medical Science and Discovery. 